\title{
Antimicrobial activity of different filling pastes for deciduous tooth treatment
}

Bruna Feltrin ANTONIAZZI(a) Carine Weber PIRES(a) Carmela Rampazzo BRESOLIN ${ }^{(a)}$ Rita Niederauer WEISS(b) Juliana Rodrigues PRAETZEL ${ }^{(a)}$

(a) Universidade Federal de Santa Maria UFSM, School of Dentistry, Department of Stomatology, Santa Maria, RS, Brazil.

(b) Universidade Federal de Santa Maria UFSM, Department of Microbiology, Santa Maria, RS, Brazil.

Declaration of Interests: The authors certify that they have no commercial or associative interest that represents a conflict of interest in connection with the manuscript.

Corresponding Author:

Bruna Feltrin Antoniazzi

E-mail: bruantoniazzi@gmail.com

DOI: 10.1590/1807-3107BOR-2015.vol29.0005

Submitted: Jan 21, 2014

Accepted for publication: Aug 13, 2014

Last revision: Oct 16, 2014
Abstract: Guedes-Pinto paste is the filling material most employed in Brazil for endodontic treatment of deciduous teeth; however, the Rifocort ${ }^{\circledR}$ ointment has been removed. Thus, the aim of this study was to investigate the antimicrobial potential of filling pastes, by proposing three new pharmacological associations to replace Rifocort ${ }^{\circledR}$ ointment with drugs of already established antimicrobial power: Nebacetin ${ }^{\circledast}$ ointment, $2 \%$ Chlorhexidine Gluconate gel, and Maxitrol ${ }^{\circledast}$ ointment. A paste composed of Iodoform, Rifocort ${ }^{\circledR}$ ointment and Camphorated Paramonochlorophenol (CPC) was employed as the gold standard (G1). The other associations were: Iodoform, Nebacetin ${ }^{\circledast}$ ointment and CPC (G2); Iodoform, 2\% Chlorhexidine Digluconate gel and CPC (G3); Iodoform, Maxitrol ${ }^{\circledR}$ ointment and CPC (G4). The associations were tested for Staphylococcus aureus (S. aureus), Streptococcus mutans (S. mutans), Streptococcus oralis (S. oralis), Enterococcus faecalis (E. faecalis), Escherichia coli (E. coli), and Bacillus subtilis (B. subtilis), using the methods of dilution on solid medium - orifice agar - and broth dilution. The results were tested using statistical analysis ANOVA and Kruskal-Wallis. They showed that all the pastes had a bacteriostatic effect on all the microorganisms, without any statistically significant difference, compared with G1. S. aureus was statistically significant (multiple comparison test of Tukey), insofar as G2 and G3 presented the worst and the best performance, respectively. All associations were bactericidal for E. coli, S. aureus, S. mutans and S. oralis. Only G3 and G4 were bactericidal for E. faecalis, whereas no product was bactericidal for $B$. subtilis. Thus, the tested pastes have antimicrobial potential and have proved acceptable for endodontic treatment of primary teeth.

Keywords: Tooth, Deciduous; Root Canal Obturation; Microbial Sensitivity Tests.

\section{Introduction}

One of the purposes of the pediatric dental clinic is to maintain primary teeth in anatomical and functional condition until their normal exfoliation, insofar as these teeth perform important roles, such as aesthetic, phonetic and morphological functions. ${ }^{1}$ Oftentimes, dental traumas or extensive caries lesions affect the pulp of deciduous teeth, making the maintenance of these on the arc dependent on endodontic treatment.

Use of the pulpectomy technique on deciduous dentition has several obstacles, such as molar root curvature, root canal complexity and physiological resorption. ${ }^{2}$ In addition to these difficulties, there is the 
infection of root canals, of polymicrobial origin. ${ }^{3,4}$ For all of these reasons, the chemical-mechanical preparation of these root canals becomes complex, requiring the reduction or elimination of any bacteria with antimicrobial irrigants and, especially, with an antimicrobial filling material of vast microbial spectrum, good diffusion and resorbability.

The filling materials most commonly employed for pulp therapy in deciduous teeth are zinc oxide paste (OZE), iodoform-based paste (IBP) and calcium hydroxide ( $\mathrm{HCa})$, among others.,6 In addition, in Brazil, the most widely used filling paste is GuedesPinto paste, ${ }^{7,8}$ a drug combination composed of Iodoform, Rifocort ${ }^{\circledR}$ ointment and Camphorated Paramonochlorophenol (CPC), ${ }^{9}$ which has shown great potential as a antimicrobial and biocompatible filling material for primary teeth. ${ }^{10,11}$ However, one of its components - Rifocort ${ }^{\circledR}$ ointment - composed of an association of antibiotic (Sodium Rifamycin SV) with corticosteroid (21-prednisolone acetate) was removed from the market, restricting current use of this paste.

Therefore, this study aimed at investigating the antimicrobial potential of filling pastes, by proposing three new pharmacological associations to replace Rifocort ${ }^{\circledR}$ ointment with drugs of already established antimicrobial power.

The null hypothesis is that all the tested pastes have the same antimicrobial potential.

\section{Methodology}

The antimicrobial activity of different pastes was tested against standard strains of microorganisms obtained from a reference collection of the National Institute of Quality Control in Health (NIQCH) of the Osvaldo Cruz Foundation (FIOCRUZ, Rio de Janeiro, Brazil).
Specimens of S. aureus (ATCC 29213), S. mutans (ATCC 25175), S. oralis (ATCC 10557), E. (ATCC 29212), E. coli (ATCC 25922) and B. subtilis (ATCC 6633) were used.

The association composed of Iodoform (Biodinâmica, Ibiporã, Brazil) (0.30 g), Rifocort ${ }^{\circledR}$ (Medley S.A., Campinas, Brazil) (0.25 g) and CPC (Biodinâmica, Ibiporã, Brazil) 3:7 (0.1 mL), was employed as the gold standard (G1). In obtaining the test paste, Riforcor ${ }^{\circledR}$ was replaced, using the same amount of Nebacetin ${ }^{\circledR}$ (Nycomed Pharma, Santo Amaro, Brazil) ointment (G2), 2\% Chlorhexidine Digluconate gel (Nova Derme, Santa Maria, Brazil) (G3) and Maxitrol ${ }^{\circledR}$ (Alcon, Sao Paulo, Brazil) ointment (G4). The proportions of all the groups were distributed according to a digital analytical scale (Marte AS2000. Marte ${ }^{\circledR}$, Sao Paulo, Brazil). The different properties of each material can be found in Table 1 .

The method to evaluate the bacteriostatic activity was Dilution on Solid Medium - Orifice Agar. ${ }^{12}$ The analyses were performed in triplicate. Each microbial strain suspension was adjusted to the turbidity level, corresponding to tube \#1 of the McFarland scale, for an approximate concentration of $3 \times 10^{8}$ cells per $\mathrm{mL}$. Seventy-eight plates were prepared, 18 for G1 paste (6 microorganisms in triplicate); 18 for G2 paste; 18 for G3 paste; and 18 for G4 paste. Six control plates were prepared without the addition of pastes, to confirm the bacterial growth on the pour-plate, at $37^{\circ} \mathrm{C}$, for $24 / 48$ hours.

After the Petri plates were prepared with Brain Hearth Infusion medium (BHI - HiMedia ${ }^{\circledR}$, Mumbai, India) $+2 \%$ of pure Agar (Merck, Darmstadt, Germany) [plus 5\% defibrinated sheep blood (Laborclin, Pinhais, Brazil), for S. mutans and S. oralis], the new cultures were separated (18/24 hours) on BHI broth, into

Table 1. Different properties of each material.

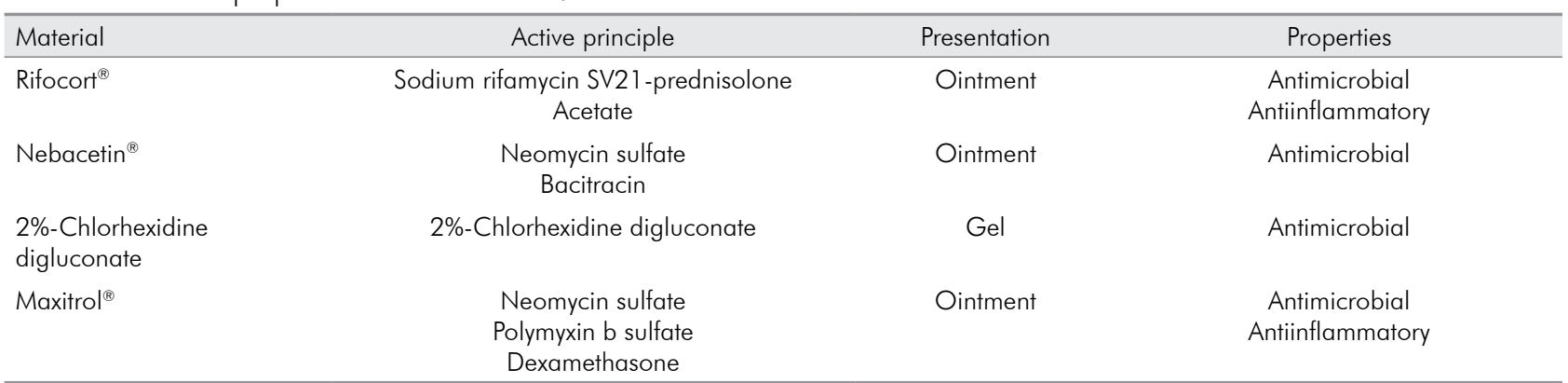


standard strains of bacteria, which were used to indicate the antimicrobial activity of the pastes.

The procedure for pour-plate preparation consisted of mixing $0.5 \mathrm{~mL}$ of recent culture with $4.5 \mathrm{~mL}$ of melted, sterilized agar. This mixture was poured into a Petri plate, onto the particular medium, using circular motions until it filled the plate and solidified. A hole was made in the center of each plate to add the materials. The hole made in the agar for placement of the pastes was performed with a sterile tube specifically for this purpose. The hole depth and diameter were $3 \mathrm{~mm}$ and $15 \mathrm{~mm}$, respectively. The bottom of the hole was sealed with melted BHI agar to avoid leakage of the pastes.

The procedure for paste preparation consisted of placing the components in ceramic mortar and mixing them with a pestle, using circular motions until the paste appeared smooth and homogeneous. The mixture was placed in a $3 \mathrm{~mL}$ disposable sterile syringe (Plastipak ${ }^{\mathrm{TM}}$, Curitiba, Brazil) to facilitate accurate application.

The plates were then identified and $0.2 \mathrm{~mL}$ of each paste were dispensed into previously prepared holes. They were left undisturbed for 15 minutes to allow for product diffusion, and were incubated at $37^{\circ} \mathrm{C}$ for $24 / 48$ hours.

The reading of the plates was performed in $24 / 48$ hours to observe bacteriostatic activity. A transparent and smooth track around the orifice, corresponding to inhibition of bacterial growth, was observed with the naked eye on an illuminated background to obtain the results. The measurement was performed using a millimeter ruler from the edge of the opening in the agar to the end of the area observed. The agar in the area where the product does not act appeared opaque from bacterial growth.

A sample of the inhibition range of each paste tested was collected with a bacteriological loop to investigate the bactericidal activity. Each sample was placed in nutrient broth for $24 / 48$ hours to determine bacterial growth, which was observed as turbidity of the medium. Since the medium did not become turbid, the bactericidal action was confirmed. When there was bacterial growth, the test organism was confirmed by chiming in nutrient agar.

The data were analyzed with the SPSS program for Windows 15.0 (SPSS Inc., Chicago, USA). Data normality was tested with the Shapiro-Wilk test. ANOVA was used for variables that represent the microorganisms, and showed normal distribution, whereas Kruskal-Wallis was used for non-normal variables. A significance level of $5 \%$ was considered.

\section{Results}

The analytical statistics of data on measures of central tendency (mean or median) and dispersion (1Q3 or standard deviation) of the growth inhibition tracks of microorganisms tested are shown in Table 2.

Analyzing the pastes in regard to bacteriostatic capacity, it was observed that all the pastes, including G1 paste, were bacteriostatic against all the organisms tested.

Pastes G2, G3 e G4 performed similarly in regard to bacteriostatic activity, when comparing their ability to control E. faecalis, E. coli, B. subtilis, S. oralis and S. mutans microorganisms. However, an analysis of Table 2 shows that there was a statistically significant difference for

Table 2. Measures of central tendency and dispersion of the growth inhibition tracks of microorganisms tested and significance $\left(^{*}\right)$.

\begin{tabular}{|c|c|c|c|c|c|}
\hline \multirow{2}{*}{ Microorganism } & \multicolumn{4}{|c|}{ Median (1Q3) } & \multirow{2}{*}{$p$ value } \\
\hline & G1 & G2 & G3 & G4 & \\
\hline E. Faecalis & $10(8-11)^{a}$ & $11(11-12)^{a}$ & $12(11-13)^{a}$ & $9(8-12)^{a}$ & 0.193 \\
\hline E. Coli & $7(7-11)^{b}$ & $7(7-7)^{b}$ & $6(6-7)^{b}$ & $8(7-8)^{b}$ & 0.108 \\
\hline B. Subtilis & $34(34-34)^{c}$ & $34(22-34)^{c}$ & $34(34-34)^{c}$ & $27(25-30)^{c}$ & 0.082 \\
\hline S. Oralis & $22(20-25)^{d}$ & $18(18-20)^{d}$ & $15(14-23)^{d}$ & $21(19-25)^{d}$ & 0.247 \\
\hline \multicolumn{6}{|c|}{ Mean (sd) } \\
\hline S. Aureus & $6( \pm 1.000)^{e}$ & $5( \pm 0.000)^{f}$ & $10( \pm 2.000)^{g}$ & $7.33( \pm 2.51)^{\mathrm{e}}$ & $0.01 *$ \\
\hline S. Mutans & $16( \pm 3.60)^{h}$ & $16( \pm 2.646)^{\mathrm{h}}$ & $16( \pm 2.646)^{h}$ & $17( \pm 1.000)^{\mathrm{h}}$ & 0.954 \\
\hline
\end{tabular}

Different letters in rows indicate significant differences $(p \leq 0.05)$. 
S. aureus, as tested by ANOVA. This difference was observed by applying the Tukey multiple comparison test, according to which the difference was found to be between G2 and G3, which showed the worst and the best performance, respectively.

Evaluating the pastes for bactericidal capacity, it was observed that the E. coli, S. aureus, S. oralis and S. mutans microorganisms were sensitive to their bactericidal effect in all the groups. Only groups G3 and G4 showed bactericidal activity for E. faecalis, and no group was bactericidal for the B. subtilis microorganism.

\section{Discussion}

This study was developed because of the need to find a filling material to treat deciduous teeth, having optimal antimicrobial potential and good diffusion, and being resorbable. The results showed that the null hypothesis was accepted, since all the pastes tested showed similar antimicrobial activity, compared with Guedes-Pinto paste.

The OZE is widely used in the endodontic treatment of primary teeth. However, despite high success rates, there are disadvantages involving the difference between the degree of tooth resorption and the paste. ${ }^{13}$ Moreover, if the paste is forced through the radicular apex, there is a risk of causing a deviation of the eruption trajectory of the permanent successor tooth. ${ }^{14}$ The HCa paste is another optional filling material, due its favorable properties, such as biocompatibility, as well as bactericidal, resorbable and radiopaque features. ${ }^{15}$ However, its use is associated with internal resorption. ${ }^{16}$

The IBP have long been applied in dentistry. ${ }^{17}$ Guedes-Pinto paste is one such paste, and has demonstrated high rates of clinical and radiographic success in pulpotomies ${ }^{18}$ and pulpectomies. ${ }^{19}$ However, the fact that one of the components of the original paste is no longer available on the market has required that alternative components be found and researched to make a similar paste.

An important consideration in choosing the materials to be used was that $2 \%$ Chlorhexidine Digluconate gel is a potent antimicrobial agent widely used in dentistry for disinfecting root canals, and has a very high therapeutic index in endodontics. ${ }^{20}$ This agent delivers excellent action against gram-positive and gram-negative bacteria, offers 12 weeks of dentine substantivity, and is biocompatible with the periapical tissues. ${ }^{21}$ However, studies suggest that chlorhexidine in high concentrations, as that used in this study, poses a potential systemic risk by producing reactive oxygen species (ROS), causing oxidative damage to deoxyribonucleic acid (DNA), and the release of para-chloroaniline, a cytotoxic agent with carcinogenic potential in humans..$^{22,23}$

Although Nebacetin ${ }^{\circledast}$ ointment and Maxitrol ${ }^{\circledR}$ ointment are not used in dental treatment, they have already established antimicrobial power in their respective uses. Maxitrol ${ }^{\circledR}$ ophthalmic ointment has a composition similar to that of Rifocort ${ }^{\circledR}$, insofar as it is composed of associations of corticosteroids (Dexamethasone) and antibiotics (Neomycin Sulfate and Polymyxin B Sulfate), and is used in ocular inflammatory conditions from bacterial infection. ${ }^{24}$

Nebacetin ${ }^{\circledast}$ ointment consists of the association of two antibiotics - Bacitracin and Neomycin Sulfate. It provides bactericidal action against both gram positive and gram negative bacteria, and is used to treat infections of the skin and mucosa. ${ }^{25}$ These drugs were selected not only for these characteristics, but also because they have no contraindication regarding drug interaction with the other components of the paste.

However, the antimicrobial activity of associations is only the first step, since a balance needs to be reached between this feature and cytocompatibility. Thus, after the antimicrobial effect has been proven, the biocompatibility of the pastes must be tested by many parameters, such as genotoxicity, mutagenicity, carcinogenicity, cytotoxicity, histocompatibility and microbial effects. ${ }^{26}$

In spite of the proven presence of strictly anaerobic microorganisms in pathogenic pulp flora, pure aerobic and facultative anaerobic cultures were chosen, because these microorganisms are most commonly used in studies that test the antimicrobial activity of materials used in endodontic therapy. ${ }^{4,27}$ Furthermore, studies show that the microbiota of root canals with endodontic failure is usually composed of facultative anaerobic gram-positive bacteria. ${ }^{3,4,28}$

The bacteriostatic and bactericidal power of an antimicrobial drug should be considered in 
determining its potential. Regarding bacteriostatic power, G1 paste demonstrated this potential in all the microorganisms tested, as already shown. ${ }^{11,27}$ Similarly, all paste tests showed this property for all microorganisms. When G2 and G3 pastes were tested against $S$. aureus, they were statistically different, compared with the control paste, i.e., G2 underperformed regarding inhibition halos and G3 had the best performance. The superiority of G3 against $S$. aureus could be related to its proven efficacy as an antimicrobial agent in infected root canals, ${ }^{29}$ and its diffusion power. Because Nebacetin ${ }^{\circledR}$ ointment is a drug that meets practically all the criteria for an ideal antibiotic, considering that it has broad spectrum bactericidal activity (including gram-positive and gram-negative action), the inferiority of the G2 paste can be explained by its consistency, which could have hindered the diffusion of this paste in the medium.

In relation to bactericidal activity, all the pastes demonstrated this characteristic against $S$. aureus, S. mutans, S. oralis and E. coli. Only G3 and G4 pastes were bactericidal for E. faecallis, and no paste showed bactericidal power against the B. subtilis microorganism. These results corroborate the findings of previous studies, where the G1 paste was not bactericidal for E. faecallis and B. subtilis microorganisms. ${ }^{27}$

Because $B$. subtilis is not a microorganism found in pathogenic oral flora, the above result has no

\section{References}

1. Imparato JCP, Duarte DA, Manfro ARG. Odontopediatria: Prática de saúde baseada em evidências. 1st ed. São Paulo: Elsevier; 2012.

2. Cleghorn BM, Boorberg NB, Christie WH. Primary human teeth and their root canal systems. Endod Topics. 2010 Sep;23(1):63-33.

3. Ruviére DB, Leonardo MR, Silva LAB, Ito IY, Nelson-Filho P. Assessment of the microbiota in root canals of human primary teeth by checkerboard DNA-DNA hybridization. J Dent Child (Chic). 2007 May-Aug;74(2):118-23.

4. Silva LAB, Nelson-Filho P, Faria G, Souza-Gugelmin MCM, Ito IY. Bacterial profile in primary teeth with necrotic pulp and periapical lesions. Braz Dent J. 2006 Apr-Jun;17(2):144-8.

5. Barja-Fidalgo F, Moutinho-Ribeiro M, Oliveira MA, de Oliveira BH. A systematic review of root canal filling materials for deciduous teeth: is there an alternative for zinc oxide-eugenol?. ISRN Dent. 2011 Jan;2011:367318. DOI: 10.5402/2011/367318. clinical relevance in the endodontic treatment of primary teeth. As already described, this bacterium was used because it served as a quality parameter in sensitivity tests of antimicrobial agents, which demonstrated excellent action. ${ }^{30}$

The resistance of the E. faecalis microorganism to antimicrobial agents, as already demonstrated, ${ }^{4,28}$ was confirmed in this study. This finding is clinically relevant for the filling of deciduous teeth, because this organism has been found in infected root canals. ${ }^{3}$

The aim of achieving pharmacological associations of filling materials for primary teeth, having antimicrobial power able to act on endodontic pathogenic flora, was achieved in its first stage.

\section{Conclusion}

The antimicrobial potential evidenced in tested pharmacological associations showed that they are capable of being used in the endodontic treatment of primary teeth. However, further studies are required to evaluate the tissue compatibility of associations, so as to allow their clinical use.

\section{Acknowledgements}

We would like to thank the Stomatology and Microbiology departments of the Universidade Federal de Santa Maria - UFSM for their support in this study.

6. Barcelos R, Santos MP, Primo LG, Luiz RR, Maia LC. ZOE paste pulpectomies outcome in primary teeth: a systematic review. J Clin Pediatr Dent. 2011 Spring;35(3):241-8.

7. Bergoli AD, Primosch RE, Araujo FB, Ardenghi TM, Casagrande L. Pulp therapy in primary teeth--profile of teaching in Brazilian dental schools. J Clin Pediatr Dent. 2010 Winter;35(2):191-5.

8. Kramer PF, Faraco-Júnior IM, Feldens CA. [Current status of pulp therapy in Brazilian Universities, pulpotomy and pulpectomy in primary teeth]. J Bras Odontopediatr Odontol Bebe. 2000 May-Jun;3(3):222-30. Portuguese.

9. Guedes-Pinto AC, Paiva JG; Bozzola JR. [Endodontic treatment of primary teeth with pulp necrosis]. Rev Assoc Paul Cir Dent. 1981;35(3):240-45. Portuguese.

10. Amorim LF, Toledo OA, Estrela CRA, Decurcio DA, Estrela C. Antimicrobial analysis of different root canal filling pastes used in pediatric dentistry by two experimental methods. Braz Dent J. 2006 Oct-Dec;17(4):317-22. 
11. Cerqueira DF, Mello-Moura ACV, Santos EM, Guedes-Pinto AC. Cytotoxicity, histopathological, microbiological and clinical aspects of an endodontic iodoform-based paste used in pediatric dentistry: a review. J Clin Pediatr Dent. 2008 Winter;32(2):105-10.

12. Romão, CMCA, Miyazaki, NHT, Motta, LLF. [Manual of sanitizers: methods for microbiological analysis of sanitizers with antimicrobial action]. Rio de Janeiro: Fundação Oswaldo Cruz; 1992. p. 65. Portuguese.

13. Tannure PN, Barcelos R, Portela MB, Gleiser R, Primo LG. Histopathologic and SEM analysis of primary teeth with pulpectomy failure. Oral Surg Oral Med Oral Pathol Oral Radiol Endod. 2009 Jul;108(1):e29-33.

14. Ranly DM, Garcia-Godoy F. Reviewing pulp treatment for primary teeth. J Am Dent Assoc. 1991 Sep;122(9):83-5.

15. Rosendahl R, Weinert-Grodd A. Root canal treatment of primary molars with infected pulps using calcium hydroxide as a root canal filling. J Clin Pediatr Dent. 1995Summer;19(4):255-8.

16. Kubota K, Golden BE, Penugonda B. Root canal filling materials for primary teeth: a review of the literature. ASDC J Dent Child. 1992 May-Jun;59(3):225-7.

17. Rifkin A. The root canal treatment of abscessed primary teeth - a three to four year follow-up. ASDC J Dent Child. 1982 Nov-Dec;49(6):428-31.

18. Bengston AL, Bengston NG. [New behavior in pulpotomies of deciduous teeth. Clinical and radiographic evaluation of the use of Guedes-Pinto paste]. RGO. 1994 Jan;42(1):7-11. Portuguese.

19. Puppin-Rontani RM, Peters CF, Worliczeck AMT. Tratamendo endodôntico de dentes decíduos com necrose pulpar. [Pulpectomy in primary teeth: a clinical investigation]. Rev Assoc Paul Cir Dent. 1994 Jan-Feb;48(1):1235-8.

20. Reddy S, Ramakrishna Y. Evaluation of antimicrobial efficacy of various root canal filling materials used in primary teeth: a microbiological study. J Clin Pediatr Dent. 2007 Spring;31(3):193-8.

21. Mohammadi Z, Abbott PV. The properties and applications of chlorhexidine in endodontics. Int Endod J. 2009 Apr;42(4):288-302.
22. Barbin LE, Saquy PC,Guedes DF, Souza-Neto MD, Estrela C, Pécora JD. Determination of para-chloroaniline and reactive oxygen species in chlorhexidine and chlorhexidine associated with calcium hydroxide. J Endod. 2008 Dec;34(12):1508-14.

23. Barbin LE, Estrela C, Guedes DF, Spanó JCE, Souza-Neto MD, Pécora JD. Detection of para-chloroaniline, reactive oxygen species, and 1-chloro-4-nitrobenzene in high concentrations of chlorhexidine and in a mixture of chlorhexidine and calcium hydroxide. J Endod. 2013 May;39(5):664-668.

24. Shulman DG, Sargent JB, Stewart RH, Mester U. Comparative evaluation of the short-term bactericidal potential of a steroid-antibiotic combination versus steroid in the treatment of chronic bacterial blepharitis and conjunctivitis. Eur J Ophthalmol. 1996 Oct-Dec;6(4):361-7.

25. Spann CT, Taylor SC, Weinberg JM. Topical antimicrobial agents in dermatology. Dis Mon. 2004 Jul;50(7):407-21.

26. Hauman $\mathrm{CH}$, Love RM. Biocompatibility of dental materials used in contemporary endodontic therapy: a review. Part 1. Intracanal drugs and substances. Int Endod J. 2003 Feb;36:(2)75-85.

27. Praetzel JR, Ferreira FV, Weiss RN, Friedrich RS, GuedesPinto AC. Antimicrobial action of a filling paste used in pulp therapy in primary teeth under different storage conditions. J Clin Pediatr Dent. 2008 Winter;33(2):113-6.

28. Estrela C, Bammann LL, Pimenta FC, Pécora JD. Control of microorganisms in vitro by calcium hydroxide pastes. Int Endod J. 2001 Jul;34(5):341-5.

29. Ruiz-Esparza CL, Garrocho-Rangel A, Gonzalez-Amaro AM, Flores-Reyes H, Pozos-Guillen AJ. Reduction in bacterial loading using $2 \%$ chlorhexidine gluconate as an irrigant in pulpectomized primary teeth: a preliminary report. J Clin Pediatr Dent. 2011 Spring;35(3):265-70.

30. Spicher G, Peters J. [Suitability of Bacillus subtilis and Bacillus stearothermophilus spores as test organism bioindicators for detecting superheating of steam]. Zentralbl Hyg Umweltmed. 1997 Feb;199(5):462-74. German. 